\title{
Outcomes differ in patients who undergo immediate intraoperative revision versus patients with delayed postoperative revision of residual lesions in congenital heart operations
}

\author{
Meena Nathan, MD, ${ }^{a}$ Kimberlee Gauvreau, ScD, ${ }^{\mathrm{b}}$ Hua Liu, MS, ${ }^{\mathrm{a}}$ Frank A. Pigula, MD, ${ }^{\mathrm{a}}$ \\ John E. Mayer, MD, ${ }^{a}$ Steven D. Colan, MD, ${ }^{b}$ and Pedro J. del Nido, MD ${ }^{a}$
}

\begin{abstract}
Objectives: In a previous study of infants less than 6 month old, we found that delayed revision of residual lesions resulted in worse patient outcomes compared with intraoperative revision. We explored a larger cohort to determine if this finding persisted.
\end{abstract}

\begin{abstract}
Methods: A prospective cohort followed from index surgery to discharge from January 2011 to September 2013 were divided into 4 groups: (1) intraoperative revisions (IO) of residual lesions, (2) delayed postoperative revision (PO) of residual lesions during the same hospital stay, (3) both intraoperative and delayed (BOTH) revision of residual lesions, (4) no intraoperative or postoperative revision (NO). Linear and logistic regression analyses were used to compare outcomes of postoperative hospital length of stay, postoperative adverse events (AE), hospital costs, and mortality, after adjusting for age, prematurity, presence of extracardiac anomalies, and RACHS-1 (Risk Adjustment for Congenital Heart Surgery-1) risk category known to affect outcomes.
\end{abstract}

Results: Of the 2427 patients discharged after a congenital cardiac operation, 1886 were eligible for this study after exclusion of adults, procedures performed off cardiopulmonary bypass, and transplants and assist devices. On multivariable modeling adjusting for other significant patient factors, the NO group fared better than the other 3 groups. The IO group had significantly lower postoperative length of stay, AE rate, and hospital costs compared with the PO and BOTH groups, but showed no significant differences in mortality.

Conclusions: Intraoperative correction of residual lesions results in shorter length of stay, and lower postoperative $\mathrm{AE}$ and costs compared with delayed postoperative revision of residual lesions. (J Thorac Cardiovasc Surg 2014;148:2540-7)

See related commentary on pages $2548-9$.

Supplemental material is available online.

Outcomes after congenital cardiac surgery depend on multiple factors including preoperative, intraoperative, and postoperative factors and events. ${ }^{1-3}$ Technical adequacy of repair is likely a significant determinant of a successful outcome. ${ }^{4-13}$ A technically optimal result may sometimes require intraoperative revision of residual defects. In addition, a technically optimal repair may be

From the Departments of Cardiac Surgery a and Cardiology, ${ }^{\mathrm{b}}$ Boston Children's Hospital and Harvard Medical School, Boston, Mass.

Disclosures: Authors have nothing to disclose with regard to commercial support.

Read at the 94th Annual Meeting of The American Association for Thoracic Surgery, Toronto, Ontario, Canada, April 26-30, 2014.

Received for publication April 28, 2014; revisions received July 7, 2014; accepted for publication July 20, 2014; available ahead of print Aug 28, 2014.

Address for reprints: Meena Nathan, MD, Department of Cardiac Surgery, Boston Children's Hospital, Harvard Medical School, 300 Longwood Ave, Boston, MA 02215 (E-mail: meena.nathan@cardio.chboston.org).

0022-5223/ $\$ 36.00$

Copyright (c) 2014 by The American Association for Thoracic Surgery

http://dx.doi.org/10.1016/j.jtcvs.2014.07.073 able to neutralize the detrimental effects of poor preoperative physiology or case complexity. ${ }^{6}$ In previous work on a group of infants less than 6 months of age at surgery, ${ }^{7}$ we were able to demonstrate that intraoperative recognition and correction of major residual defects resulted in better outcomes, even at the expense of a second bypass run with resultant longer support and ischemic times. We wished to determine if this remained true in a larger cohort of patients encompassing a wide range of age and disease complexity.

\section{METHODS}

Consecutive patients who were discharged after congenital heart surgery from January 2011 to September 2013 were followed prospectively from admission to discharge with institutional review board approval. We excluded patients aged 18 years or more, procedures performed off cardiopulmonary bypass, and transplants and assist devices. Only the index surgery for each admission was included in the analysis. The Risk Adjustment for Congenital Heart Surgery-1 (RACHS-1) categories ${ }^{14,15}$ and the Society of Thoracic Surgeons-European Association for Cardio-Thoracic Surgery (STAT) mortality categories ${ }^{16,17}$ were used to determine case complexity. The occurrence of intraoperative reintervention for residual defects, and postoperative unplanned reinterventions for residual defects in anatomic areas operated at the index surgery were recorded. Major postoperative adverse events (AEs) as defined by the Society of Thoracic Surgeons (STS) congenital heart surgery database criteria (excluding unplanned reinterventions in the anatomic area of repair at index surgery), mortality, postoperative 


\begin{tabular}{|c|c|}
\hline \multicolumn{2}{|c|}{ Abbreviations and Acronyms } \\
\hline $\mathrm{AE}$ & $=$ adverse event \\
\hline ВOTH & $\begin{aligned}= & \text { both intraoperative and delayed } \\
& \text { postoperative revision }\end{aligned}$ \\
\hline EACTS & $\begin{aligned}= & \text { European Association for Cardio- } \\
& \text { Thoracic Surgery }\end{aligned}$ \\
\hline IO & $=$ intraoperative revision \\
\hline NO & $\begin{aligned}= & \text { no intraoperative or postoperative } \\
& \text { revision }\end{aligned}$ \\
\hline $\mathrm{PO}$ & $=$ delayed postoperative revision \\
\hline \multicolumn{2}{|c|}{$\begin{aligned} \text { RACHS-1 } & =\text { risk adjustment in congenital heart } \\
& \text { surgery }\end{aligned}$} \\
\hline STAT & $\begin{aligned}= & \text { Society of Thoracic Surgeons- } \\
& \text { European Association for Cardio- } \\
& \text { Thoracic Surgery mortality categories }\end{aligned}$ \\
\hline STS & $=$ Society of Thoracic Surgeons \\
\hline TEE & $=$ transesophageal echocardiography \\
\hline
\end{tabular}

length of hospital stay, and total hospital costs were obtained. Additional information on risk factors such as prematurity, presence of chromosomal and other noncardiac anomalies, and patient demographics such as age and gender were documented.

\section{Categorization of Revisions for Residual Lesions (Revision Groups)}

The entire patient cohort was categorized into 4 groups: (1) intraoperative revision (IO) of residual lesions, (2) delayed postoperative revision (PO) of residual lesions during the same hospital stay, (3) both intraoperative and delayed (BOTH) revision of residual lesions, (4) no intraoperative or postoperative revisions $(\mathrm{NO})$.

\section{RACHS-1 Risk Categories}

The RACHS-1 method was developed to adjust for baseline case mix differences in risk when comparing in-hospital mortality among groups of patients less than 18 years of age undergoing congenital heart surgery. Surgical procedures were placed into 6 predefined categories with similar risks for in-hospital mortality; category 1 had the lowest risk for death and category 6 the highest. Cases with combinations of cardiac surgical procedures (eg, repair of coarctation of the aorta and ventricular septal defect closure) were placed in the risk category corresponding to the single highest risk procedure. ${ }^{14,15}$ In order to be able to evaluate the entire study cohort, including those for whom the original RACHS-1 method was not validated, we used category 7 to represent patients who underwent a cardiac surgical procedure that was not included in the RACHS-1 method (eg, biventricular recruitment, biventricular conversion from single-ventricle palliation, and so forth).

\section{STAT Mortality Categories}

STAT mortality categories were developed using a Bayesian model based on more than 75,000 congenital cardiac operations entered either in the STS congenital heart surgery database or the congenital heart surgery databases of the European Association for Cardio-Thoracic Surgery (EACTS) between 2002 and 2007. ${ }^{16,17}$ Congenital cardiac operations were divided into 5 homogeneous categories with increasing risk of mortality. This method of risk stratification was further validated in subsequent studies and is currently used for risk stratification in the STS and EACTS congenital heart surgery database analyses for patients of all ages. STAT category 1 has the lowest risk of mortality and STAT category 5 has the highest risk of mortality. For the purposes of this study, an additional category (category 6) was created to include all procedures that could not be assigned to the existing STAT categories (eg, biventricular conversion after single-ventricle palliation).

\section{Outcomes}

The primary outcome of interest was postoperative hospital length of stay. The secondary outcomes included in this analysis were major postoperative AEs, early mortality, and total hospital costs. Postoperative hospital length of stay was defined as length of hospital stay beginning from the day of index surgery until discharge from hospital. Early mortality was defined as death while in hospital or death within 30 days of index operation if discharged before 30 days. ${ }^{18}$ Major postoperative AEs were defined according to the STS congenital heart surgery database classification $^{19}$ and included the following: (1) need for extracorporeal membrane oxygenator support, (2) reexploration for bleeding, (3) cardiac arrest requiring resuscitation, (4) reexploration for hemodynamic instability, (5) diaphragm plication for paralysis/paresis of the diaphragm, (6) stroke, (7) mediastinitis requiring exploration and debridement, and (8) renal failure requiring dialysis. Unplanned surgical or catheter-based reinterventions in the anatomic area operated on and placement of permanent pacemakers were not included as AEs as they are used to define the revision groups. Hospital charges for each surgical admission were obtained from the hospital's cost accounting database. Costs were then calculated based on the cost to charge ratio for each fiscal year.

\section{Statistical Analysis}

Categorical variables are summarized as numbers and percentages, and continuous variables as medians and ranges or interquartile range as indicated. Patient risk factors and outcomes were compared across the 4 revision groups using the $\chi^{2}$ test for categorical variables and the Kruskal-Wallis test for continuous variables. In order to adjust for baseline patient characteristics when examining differences in outcomes among the 4 revision groups, multivariable logistic and linear regression analyses were used. Intraoperative revisions were used as the reference category and indicator variables were created for each of the 3 other revision groups. Discrimination of the logistic regression models for predicting mortality and major postoperative AEs was assessed using the area under the receiver-operator characteristic curve. For the linear regression model for postoperative hospital length of stay and total hospital costs, the coefficient of determination is presented. Because both postoperative hospital length of stay and total hospital cost have skewed distributions, a log transformation was applied. Regression coefficients and odds ratios are presented with 95\% confidence intervals. SAS version 9.2 (SAS Institute Inc, Cary, NC) was used for the statistical analysis.

\section{RESULTS}

There were 1886 eligible patients included in the study from 2427 consecutive patient discharges between January 2011 and September 2013. Among the entire cohort, 829 $(44 \%)$ were girls. The median age was 1.2 years (range, 0 days to 17.9 years); 145 (8\%) were premature, and 390 $(21 \%)$ had some form of extracardiac congenital anomaly or genetic anomaly. The distribution among the RACHS-1 risk categories was as follows: $164(9 \%)$ category 1,586 $(31 \%)$ category 2, $676(36 \%)$ category 3, $208(11 \%)$ category 4, $71(4 \%)$ category 6 , and $181(10 \%)$ category 7 (no RACHS category). The distribution among the STAT categories was as follows: $650(34 \%)$ category 1,525 $(28 \%)$ category $2,183(10 \%)$ category $3,376(20 \%)$ 
category $4,105(6 \%)$ category 5 , and $47(2 \%)$ category 6 (no STAT category). The distribution of the revision categories was as follows: $1658(88 \%) \mathrm{NO}, 81(4 \%) \mathrm{IO}, 128(7 \%)$ $\mathrm{PO}$, and $19(1 \%)$ BOTH. The baseline patient characteristics among the 4 revision groups and outcomes of interest are represented in Table 1 . The types of intraoperative and postoperative revisions in the IO, $\mathrm{PO}$, and BOTH groups are shown in the Online Data Supplement Tables E1 to E3.The median postoperative hospital length of stay was 7 days (25th and 75th percentiles, 5 and 13 days, respectively); the AE rate, excluding unplanned surgical or catheter-based reinterventions in the anatomic area repaired at the index operation, was $5.3 \%$ (100); and the mortality rate was $2.1 \%$ (39). The hospital costs are represented in Table 1.

\section{Postoperative Hospital Length of Stay}

Postoperative hospital length of stay varied across the 4 revision groups, with the $\mathrm{PO}$ and BOTH groups having longer median length of stay than the NO and IO groups $(P<.001$, Table 1, Figure E1). Patient factors associated with longer length of stay were neonatal age, prematurity, higher RACHS-1 risk category or STAT mortality category, and the presence of chromosomal or other extracardiac anomalies (Table E4). After adjusting for significant baseline patient characteristics, both the PO and BOTH revision groups had significantly longer length of stay than the IO group $(P<.001$ and $P=.001$ respectively); the NO group had significantly shorter length of stay $(P=.028)$ (Table 2$)$.

\section{Postoperative AEs}

Similarly, postoperative AEs varied significantly across the 4 revision groups; the $\mathrm{PO}$ and BOTH groups experienced a greater proportion of events than the $\mathrm{NO}$ and IO groups (Table 1, Figure E1). Other factors associated with postoperative AEs were younger age, higher RACHS-1 or STAT category, prematurity, and chromosomal or extracardiac abnormality $(P=.03$ for anomalies and $P<.001$ for the rest; Table E4). After adjusting for significant patient risk factors, compared with the IO group, the PO and BOTH groups remained strongly associated with postoperative AEs (Table 3).

TABLE 1. Patient characteristics and outcomes by the 4 revision groups $(n=1886)$

\begin{tabular}{|c|c|c|c|c|c|}
\hline & No revisions & $\begin{array}{c}\text { Intraoperative } \\
\text { revision of residual } \\
\text { lesion } \\
\end{array}$ & $\begin{array}{c}\text { Postoperative } \\
\text { revision of residual } \\
\text { lesion } \\
\end{array}$ & $\begin{array}{c}\text { Both intra- and } \\
\text { postoperative revision } \\
\text { of residual lesion } \\
\end{array}$ & $P$ value \\
\hline Number in group $(\%)$ & $1658(88)$ & $81(4)$ & $128(7)$ & $19(1)$ & \\
\hline Median age, y (range) & $1.3(1 \mathrm{~d}-17.9)$ & $1.9(1 \mathrm{~d}-16.5)$ & $0.5(1 \mathrm{~d}-15.5)$ & $0.7(2 \mathrm{~d}-14.5)$ & $<.001$ \\
\hline Prematurity, n (\%) & $119(7)$ & $5(6)$ & $21(16)$ & $0(0)$ & .004 \\
\hline $\begin{array}{l}\text { Extracardiac/genetic } \\
\text { anomalies/syndromes, n (\%) }\end{array}$ & $333(20)$ & $21(26)$ & $29(23)$ & $7(37)$ & .16 \\
\hline RACHS-1 risk category, n (\%) & & & & & $<.001$ \\
\hline $1(164)$ & $160(10)$ & $3(4)$ & $1(1)$ & $0(0)$ & \\
\hline $2(586)$ & $543(33)$ & $25(31)$ & $18(14)$ & $0(0)$ & \\
\hline $3(676)$ & $580(35)$ & $41(51)$ & $45(35)$ & $10(53)$ & \\
\hline $4(208)$ & $172(10)$ & $8(10)$ & $26(20)$ & $2(11)$ & \\
\hline $6(71)$ & $58(4)$ & $0(0)$ & $11(9)$ & $2(11)$ & \\
\hline Not categorized, 7 (181) & $145(9)$ & $4(5)$ & $27(21)$ & $5(26)$ & \\
\hline STAT mortality category, n (\%) & & & & & $<.001$ \\
\hline $1(650)$ & $619(37)$ & $21(26)$ & $10(8)$ & $0(0)$ & \\
\hline $2(525)$ & $461(28)$ & $31(38)$ & $30(23)$ & $3(16)$ & \\
\hline $3(183)$ & $159(10)$ & $10(12)$ & $10(8)$ & $4(21)$ & \\
\hline $4(376)$ & $293(18)$ & $16(20)$ & $59(46)$ & $8(42)$ & \\
\hline $5(105)$ & $86(5)$ & $2(2)$ & $15(12)$ & $2(11)$ & \\
\hline 6 (47) (not categorized) & $40(2)$ & $1(1)$ & $4(3)$ & $2(11)$ & \\
\hline $\begin{array}{l}\text { Median postoperative hospital } \\
\text { length of stay, } d \text { ( } 25 \text { th, } 75 \text { th } \\
\text { percentiles) }\end{array}$ & $6(4,11)$ & $7(5,11)$ & $26(14,63)$ & $17(12,30)$ & $<.001$ \\
\hline $\begin{array}{l}\text { Postoperative adverse } \\
\text { events, } \mathrm{n}(\%)\end{array}$ & 48 (2.9) & $3(3.7)$ & $43(34)$ & $6(32)$ & $<.001$ \\
\hline Early mortality, n (\%) & $13(0.8)$ & $3(3.7)$ & $19(15)$ & $4(21)$ & $<.001$ \\
\hline $\begin{array}{l}\text { Median total hospital costs, } \\
\text { US\$ (25th, 75th percentiles) }\end{array}$ & $44,504(32,134,78,342)$ & $49,427(37,552,81,592)$ & $204,750(99,061,427,594)$ & $202,026(109,115,345,505)$ & $<.001$ \\
\hline
\end{tabular}


TABLE 2. Multivariable linear regression model for outcome postoperative hospital length of stay

\begin{tabular}{|c|c|c|c|}
\hline & $\begin{array}{l}\text { Regression } \\
\text { coefficient }\end{array}$ & $95 \%$ CI & $P$ value \\
\hline $\begin{array}{l}\text { Extracardiac/genetic } \\
\text { anomalies/syndromes }\end{array}$ & 1.2 & $1.1-1.3$ & $<.001$ \\
\hline Prematurity & 1.4 & $1.3-1.5$ & $<.001$ \\
\hline Neonates $(\leq 30 \mathrm{~d})$ & 1.9 & $1.8-2.1$ & $<.001$ \\
\hline Infants $(31 \mathrm{~d}$ to $<1 \mathrm{y})$ & 1.4 & $1.3-1.5$ & $<.001$ \\
\hline \multicolumn{4}{|l|}{ RACHS- 1 risk categories } \\
\hline 1 (reference) & 1.0 & - & - \\
\hline 2 & 1.3 & $1.2-1.5$ & $<.001$ \\
\hline 3 & 1.9 & $1.7-2.1$ & $<.001$ \\
\hline 4 & 2.1 & $1.9-2.4$ & $<.001$ \\
\hline 6 & 3.4 & $2.9-4.1$ & $<.001$ \\
\hline 7 (not categorized) & 2.7 & $2.4-3.1$ & $<.001$ \\
\hline \multicolumn{4}{|l|}{$\begin{array}{l}\text { Revision groups: reintervention } \\
\text { for residual lesions }\end{array}$} \\
\hline $\begin{array}{l}\text { Intraoperative reintervention } \\
\quad \text { (reference) }\end{array}$ & 1.0 & - & - \\
\hline No reintervention & 0.9 & $0.8-1.0$ & .028 \\
\hline Postoperative reintervention & 2.5 & $2.1-2.9$ & $<.001$ \\
\hline $\begin{array}{l}\text { Both intraoperative and } \\
\text { postoperative reinterventions }\end{array}$ & 1.6 & $1.2-2.2$ & .001 \\
\hline
\end{tabular}

Coefficient of determination is $\mathrm{R}^{2}=40.2 \%$ for the model that does not contain revision groups, and increases to $\mathrm{R}^{2}=50.2 \%$ when revision groups are included. $C I$, Confidence interval; RACHS-1, risk adjustment for congenital heart surgery.

\section{Early Mortality}

Similarly, early mortality (30-day or in-hospital mortality) varied significantly across the 4 revision groups; the PO and BOTH groups had a higher mortality rate than the NO and IO groups (Table 1, Figure E1). Other variables associated with mortality included younger age, higher RACHS-1 or STAT category, prematurity, and the presence of chromosomal or other extracardiac anomalies (all $P \leq$ .001 , Table E4). Adjusting for variables significant in univariate analysis and comparing the IO group with the other groups, the NO group had significantly lower mortality $(P=.02)$. However, there was no significantly higher association with mortality for the PO or BOTH groups (Table 4). The odds ratios were 2.1 and 5.5 for the PO and BOTH groups, respectively, compared with the IO group, and the BOTH group showed a trend toward significance $(P=.08)$.

\section{Total Hospital Costs}

Total hospital costs varied across the 4 revision groups; the PO and BOTH groups had higher total hospital costs than the NO and IO groups $(P<.001$, Table 1 , Figure E1). Other factors associated with longer length of stay were neonatal age, prematurity, higher RACHS-1 or STAT category, and the presence of chromosomal or other extracardiac anomalies (Table E4). After adjusting for significant baseline patient characteristics, both the PO and BOTH revision groups had significantly higher total
TABLE 3. Multivariable logistic regression model for outcome major postoperative adverse events

\begin{tabular}{lccc}
\hline & $\begin{array}{c}\text { Odds } \\
\text { ratio }\end{array}$ & $\mathbf{9 5 \%}$ CI & $\boldsymbol{P}$ value \\
\hline $\begin{array}{l}\text { Extracardiac/genetic } \\
\quad \text { anomalies/syndromes }\end{array}$ & 1.1 & $0.6-1.9$ & .71 \\
Prematurity & & & \\
Neonates ( $\leq 30 \mathrm{~d})$ & 4.9 & $2.6-8.9$ & $<.001$ \\
Infants (31 d to $<1$ y) & 3.0 & $1.4-6.4$ & .004 \\
RACHS-1 risk categories & 1.7 & $0.9-3.4$ & .10 \\
$1+2$ (reference) & & & \\
3 & 1.0 & - & - \\
4 & 1.8 & $0.9-4.0$ & .12 \\
6 & 4.4 & $1.9-10.5$ & $<.001$ \\
7 (not categorized) & 9.1 & $3.2-25.8$ & $<.001$ \\
Revision groups: reintervention for & 4.8 & $2.1-11.0$ & $<.001$ \\
$\quad$ residual lesions & & & \\
$\quad$ Intraoperative reintervention (ref) & 1.0 & - & - \\
$\quad$ No reintervention & 0.7 & $0.2-2.3$ & .49 \\
$\quad$ Postoperative reintervention & 7.4 & $2.0-27.7$ & .003 \\
$\quad$ Both intraoperative and postoperative & 9.2 & $1.8-47.3$ & .008 \\
$\quad$ reinterventions & & & \\
\hline
\end{tabular}

Major postoperative adverse events exclude unplanned surgical or catheter-based reinterventions in anatomic area of repair at the index surgery. c statistic is 0.822 for the model that does not contain revision groups, and increases to 0.879 when revision groups are included. $C I$, Confidence interval; RACHS-1, risk adjustment for congenital heart surgery.

hospital costs than the IO group $(P<.001)$, whereas the NO group had significantly lower total hospital costs than the IO group $(P=.004)$ (Table 5).

For all outcomes, the findings were similar when RACHS-1 risk categories were replaced by STAT mortality categories in the multivariable models. On further analysis of the 81 patients who underwent intraoperative revisions only, $68(84 \%)$ left the hospital with an adequate or better repair on the discharge echocardiogram. Most patients, 55 of the $81(68 \%)$, who underwent successful intraoperative revisions were in RACHS- 1 categories 2 and 3 (predominantly valve repair related), clearly indicating the importance of optimal and complete intraoperative imaging to help to determine the adequacy of the repair.

\section{Subgroup Analysis}

We performed the following additional subgroup analyses as exploratory analyses to look for trends. The BOTH group was excluded because of small sample size. The findings of the univariate analysis are presented in Table E5.

Risk-adjusted subgroup analysis by the presence or absence of valve intervention. Restricting to patients who had valve interventions at the index surgery, the relationships were similar to those in the overall cohort with the exception that there was no significant difference between the IO and NO groups for the outcomes of interest. 
TABLE 4. Multivariable logistic regression model for outcome early mortality

\begin{tabular}{lccc}
\hline & $\begin{array}{c}\text { Odds } \\
\text { ratio }\end{array}$ & $\mathbf{9 5 \%} \mathbf{C I}$ & $\boldsymbol{P}$ value \\
\hline Extracardiac/genetic & 2.6 & $1.2-5.6$ & .01 \\
$\quad$ anomalies/syndromes & & & \\
Prematurity & 5.4 & $2.3-12.4$ & $<.001$ \\
Neonates $(\leq 30 \mathrm{~d})$ & 6.4 & $1.7-24.5$ & .007 \\
Infants $(31 \mathrm{~d}$ to $<1$ y) & 2.7 & $0.8-9.2$ & .12 \\
RACHS-1 risk categories & & & \\
$1+2$ (reference) & 1.0 & - & - \\
3 & 0.9 & $0.2-3.6$ & .93 \\
4 & 3.6 & $0.9-13.7$ & .06 \\
$\quad$ 6 & 4.5 & $0.9-22.5$ & .06 \\
$\quad$ (not categorized) & 4.7 & $1.3-17.4$ & .02 \\
Revision groups: reintervention for & & & \\
$\quad$ residual lesions & & & \\
$\quad$ Intraoperative reintervention & 1.0 & - & - \\
$\quad$ (reference) & & & \\
$\quad$ No reintervention & & & \\
$\quad$ Postoperative reintervention & & & \\
$\quad$ Both intraoperative and & 2.1 & $0.5-9.5$ & .34 \\
$\quad$ postoperative reinterventions & 5.5 & $0.8-37.8$ & .08 \\
\hline
\end{tabular}

Early mortality is defined as death occurring $\leq 30$ days from the index surgery or death before hospital discharge if postoperative hospital length of stay $>30$ days. $c$ statistic is 0.886 for the model that does not contain revision groups, and increases to 0.939 when revision groups are included. $C I$, Confidence interval; RACHS-1, risk adjustment for congenital heart surgery.

Risk-adjusted subgroup analysis by age group. Restricting to patients less than 1 year of age at surgery, the relationships were similar to those in the overall cohort with the exception that for early mortality, the NO group had lower odds of death than the IO group in both age strata, but this was significant only for age less than 1 year.

Subgroup analysis of patients who had a major residual lesion to compare those who had intervention postoperatively with those without intervention. We then performed a subgroup analysis of patients with major residual lesions who required postoperative interventions and those who did not to determine factors that may be associated with unplanned reintervention for a major residual burden. The findings are presented in Table E6. To summarize, the patients who had unplanned postoperative reinterventions for major residua were significantly younger, with a higher proportion of premature infants, and had higher case complexity as determined by RACHS-1 risk categories and STAT mortality categories.

Subgroup analysis of frequency-matched groups. To help evaluate whether the differences in outcomes between revision groups were caused by residual confounding, we frequency matched subgroups of patients from the NO and PO groups to the IO group to create 3 groups of equal size that were balanced with regard to important patient risk factors for poor outcome (age, prematurity, presence of chromosomal or other extracardiac anomalies, surgical
TABLE 5. Multivariable linear regression model for outcome total hospital cost

\begin{tabular}{|c|c|c|c|}
\hline & $\begin{array}{l}\text { Regression } \\
\text { coefficient }\end{array}$ & $95 \% \mathrm{CI}$ & $P$ value \\
\hline $\begin{array}{l}\text { Extracardiac/genetic } \\
\text { anomalies/syndromes }\end{array}$ & 1.2 & $1.1-1.2$ & $<.001$ \\
\hline Prematurity & 1.4 & $1.3-1.5$ & $<.001$ \\
\hline Neonates $(\leq 30 \mathrm{~d})$ & 1.9 & $1.7-2.0$ & $<.001$ \\
\hline Infants $(31 \mathrm{~d}$ to $<1 \mathrm{y})$ & 1.3 & $1.2-1.4$ & $<.001$ \\
\hline \multicolumn{4}{|l|}{ RACHS-1 risk categories } \\
\hline 1 (reference) & 1.0 & - & - \\
\hline 2 & 1.4 & $1.3-1.5$ & $<.001$ \\
\hline 3 & 2.0 & $1.8-2.2$ & $<.001$ \\
\hline 4 & 2.4 & $2.1-2.7$ & $<.001$ \\
\hline 6 & 3.2 & $2.7-3.8$ & $<.001$ \\
\hline 7 (not categorized) & 3.0 & $2.7-3.3$ & $<.001$ \\
\hline \multicolumn{4}{|l|}{$\begin{array}{l}\text { Revision groups: reintervention } \\
\text { for residual lesions }\end{array}$} \\
\hline $\begin{array}{l}\text { Intraoperative reintervention } \\
\quad \text { (reference) }\end{array}$ & 1.0 & - & - \\
\hline No reintervention & 0.8 & $0.8-0.9$ & .004 \\
\hline Postoperative reintervention & 2.4 & $2.1-2.8$ & $<.001$ \\
\hline $\begin{array}{l}\text { Both intraoperative and } \\
\text { postoperative reinterventions }\end{array}$ & 2.3 & $1.8-3.0$ & $<.001$ \\
\hline
\end{tabular}

Coefficient of determination is $\mathrm{R}^{2}=44.5 \%$ for the model that does not contain revision groups, and increases to $\mathrm{R}^{2}=57.2 \%$ when revision groups are included. $C I$, Confidence interval; RACHS-1, risk adjustment for congenital heart surgery.

risk). As there were only 20 patients in the BOTH group, it was excluded from this analysis. The results of our analysis are shown in Table E7. In these groups with a similar profile of risk factors, the outcomes for the $\mathrm{NO}$ and IO groups are similar, but the $\mathrm{PO}$ group has significantly higher median hospital length of stay, postoperative AEs, and hospital costs. Although the mortality rate was higher in the PO group, this did not reach statistical significance because of the relatively small number of deaths in each group ( 2 in the NO group, 3 in the IO group, and 6 in the PO group).

\section{DISCUSSION}

This study demonstrates that achieving an optimal repair, with minimal or no residua, affects outcomes after congenital cardiac surgery. Achieving this ideal endpoint may in some instances require a second period of cardiopulmonary support with or without a period of myocardial ischemic arrest to surgically correct residual lesions. Identification of residual lesions is essential if optimal repair is to be achieved at the index surgery. Enhanced intraoperative imaging that can provide information on all aspects of the repair is an important factor in achieving optimal surgical results before exiting the operating room. This may require a combination of transesophageal echocardiography (TEE) and epicardial echocardiography for structures that may not be clearly visualized on TEE. ${ }^{20-22}$ The use of exit angiograms for certain procedures may be a 
consideration, particularly for complex repairs. ${ }^{23,24}$ Although imaging provides visual confirmation of the repair, clinical indicators and testing may aid in final decision making about the adequacy of repair and the need to reintervene, including direct measurements of gradients and filling pressures, and monitoring of venous and arterial saturations. ${ }^{25}$ The final decision whether to reintervene for residual lesions is determined by the severity of the residua and its effect on hemodynamics and whether reintervention on the lesion can result in an improved repair. In some situations, it may not be anatomically possible to achieve an optimal repair. The imperative is, however, to achieve as optimal a repair as anatomically possible at the index operation, as several studies have clearly shown that optimal repairs affect not only early outcomes ${ }^{4-8,12}$ such as mortality, AEs, and length of stay but also affect midterm outcomes such as postdischarge mortality, postdischarge unplanned reintervention, ${ }^{9,13}$ and even neurodevelopmental outcomes. ${ }^{26}$ Several factors are known to be associated with higher hospital costs, ${ }^{27-31}$ including prematurity, age, presence of chromosomal anomalies, and RACHS- 1 risk categories. In this study, after adjusting for baseline patient factors known to be associated with higher hospital costs, we were able to show that identification and repair of residual lesions in the operating room can significantly reduce total hospital costs.

In our analysis of outcomes, we adjusted for preoperative patient-specific variables. We did not use intraoperative variables (eg, cardiopulmonary bypass time) because of the strong collinearity between these variables (the IO and BOTH revision groups as expected had significantly longer cardiopulmonary bypass times), which would lead to confounding. In our analysis, the PO group had significantly poorer outcome than the IO group, however we did show that the NO group had better outcomes compared with the IO group. This may be because most of the low complexity cases (RACHS-1 categories 1 and 2) were represented in the NO group. In order to account for such confounding, we performed additional frequency-matched analysis outlined in Table E7. In the frequency-matched groups, none of the baseline patient risk factors were statistically significant. Despite this, there was a significant difference in outcomes. Postoperative hospital length of stay was longer in the PO group; this group is more likely to have postoperative AEs and higher median costs. The lack of difference in mortality between the groups may be attributable to the small number of deaths overall. The overall mortality for our entire cohort was only $2.1 \%(\mathrm{n}=39)$. A larger number would be needed for this to reach statistical significance. It is well known that in the current era of relatively low mortality rates, $\mathrm{AE}$ rates and resource utilization bench marks in the form of length of stay and costs are increasingly being used as a measure of quality of care.
We are currently analyzing data on intraoperative echo and decisions on intraoperative interventions in this cohort of patients. We have, however, performed a subgroup analysis of patients who underwent postoperative unplanned reinterventions for major residua and those who did not undergo such interventions, and we were able to demonstrate (Table E6) that the patients who had unplanned postoperative reinterventions for major residua were significantly younger, with a higher proportion of premature infants, and had higher case complexity as determined by RACHS-1 risk categories and STAT mortality categories.

Subgroup analyses of patients who did and did not undergo valve interventions showed that outcomes were similar to the main cohort; the PO group had a significantly worse outcome than the IO group. Comparing the NO group with the IO groups, although length of hospital stay was significantly lower, but there was no significant difference in AEs, mortality, or costs. Similarly, when we performed a subgroups analysis of patients less than 1 year of age and those more than 1 year of age, the PO group had significantly worse outcomes for infants less than 1 year of age. However, when the IO group was compared with the NO group, there was no difference in postoperative hospital length of stay and AEs, although mortality and costs were lower in the NO group.

On reviewing the use of intraoperative imaging in this cohort, $129(6.8 \%)$ patients had no intraoperative echocardiograms, of whom $11(8.5 \%)$ had major residua on postoperative imaging, $10(7.7 \%)$ of whom required $\mathrm{PO}$ revision. In addition, $34(1.8 \%)$ patients had incomplete echos, 7 $(20.5 \%)$ of whom had major residua on postoperative imaging, $6(17.8 \%)$ of whom required $\mathrm{PO}$ revision. This finding clearly supports the need for intraoperative assessment of adequacy of repair and detection of residual lesions. The trend in our center is to obtain intraoperative imaging (either a transesophageal or epicardial echocardiogram) unless contraindicated for anatomic or hemodynamic reasons, and when necessary to supplement this information with direct pressure measurements and saturation data. More than two thirds of our IO revisions were related to valve interventions. The hemodynamic conditions immediately after cardiopulmonary bypass may make accurate measurements of the severity of valvular regurgitation and stenosis difficult, however, imaging often provides useful information on anatomic variants that are likely to worsen with time (eg, valvular regurgitation secondary to prolapse of a leaflet). About $40 \%$ of PO revisions were valve related. We are currently analyzing intraoperative echocardiographic findings and postoperative echocardiographic findings with the aim of developing a score that will help to determine the need for intraoperative revisions and predict postoperative revisions. Despite our best efforts, there remain subgroups of patients with complex anatomy in whom an optimal repair may not be achievable. 
This study, despite being a prospective analysis of consecutive patients, is limited by the fact that it reflects data from a single institution. The generalizability of these findings to other national and international centers will require a prospective multicenter study.

In summary, identification and correction of residual lesions in the operating room is associated with improved outcomes. Enhanced intraoperative imaging, which can provide information on all aspects of a repair, is an important factor in achieving optimal surgical results before exiting the operating room.

\section{References}

1. de Leval MR, Carthey J, Wright DJ, Farewell VT, Reason JT. Human factors and cardiac surgery: a multicenter study. J Thorac Cardiovasc Surg. 2000;119: 661-72.

2. Barach P, Johnson JK, Ahmad A, Galvan C, Bognar A, Duncan R, et al. A prospective observational study of human factors, adverse events and patient outcomes in surgery for pediatric cardiac disease. J Thorac Cardiovasc Surg. 2008; 136:1422-8.

3. Catchpole KR, Giddings AE, De Leval MR, Peek GJ, Godden PJ, Utley M, et al Identification of systems failure in successful paediatric cardiac surgery. Ergonomics. 2006;49:567-88.

4. Larrazabal LA, del Nido PJ, Jenkins KJ, Gauvreau K, Lacro S, Colan SD, et al. Measurement of technical performance in congenital heart surgery: a pilot study. Ann Thorac Surg. 2007;83:179-84.

5. Bacha EA, Larrazabal LA, Pigula FA, Gauvreau K, Jenkins KJ, Colan SD, et al. Measurement of technical performance in surgery for congenital heart disease: the stage I Norwood procedure. J Thorac Cardiovasc Surg. 2008; 136:993-7.

6. Karamichalis JM, Thiagarajan RR, Liu H, Mamic P, Gauvreau K, Bacha EA. Stage I Norwood: optimal technical performance improves outcomes irrespective of preoperative physiologic status or case complexity. J Thorac Cardiovasc Surg. 2010;139:962-8.

7. Nathan M, Karamichalis J, Liu H, del Nido P, Pigula F, Thiagarajan R, et al. Intraoperative adverse events can be compensated in infants after cardiac surgery: a prospective study. J Thorac Cardiovasc Surg. 2011;142:1098-107.

8. Shuhaiber J, Gauvreau K, Thiagarjan R, Bacha EA, Mayer JE, del Nido PJ, et al. Congenital heart surgeon's technical proficiency affects neonatal hospital survival. J Thorac Cardiovasc Surg. 2012;144:1119-24.

9. Nathan M, Karamichalis JM, Colan S, Liu H, Pigula FA, Fynn-Thompson F, et al. Surgical technical performance scores are predictors for late mortality and unplanned reinterventions in infants after cardiac surgery. $J$ Thorac Cardiovasc Surg. 2012; 144:1095-101.

10. Karamichalis JM, Colan SD, Nathan M, Pigula FA, Baird CB, Marx G, et al. Technical performance scores in congenital cardiac surgery: a quality assessment initiative. Ann Thorac Surg. 2012;94:1317-23.

11. Karamichalis JM, Barach P, Nathan M, Henaine R, del Nido PJ, Bacha EA. Assessment of technical competency in pediatric cardiac surgery. Prog Pediatr Cardiol. 2012;33:15-20.

12. Nathan M, Karamichalis J, Liu H, Gauvreau K, Colan S, Pigula FA, et al Technical performance scores are strongly associated with early mortality, postoperative adverse events and ICU length of stay - analysis of consecutive discharges over 2 years. J Thorac Cardiovasc Surg. 2014;147:389-96.

13. Nathan M, Pigula FA, Liu H, Gauvreau K, Colan SD, Fynn-Thompson F, et al. Inadequate technical performance scores are associated with late mortality and late reinterventions. Ann Thorac Surg. 2013;96:664-9.

14. Jenkins KJ, Gauvreau K, Newburger JW, Spray TL, Moller JH, Iezzoni LI. Consensus based method for risk adjustment for surgery for congenital heart disease. J Thorac Cardiovasc Surg. 2002;123:110-8.

15. Jenkin KJ. Risk adjustment for congenital heart surgery: the RACHS-1 method. Semin Thorac Cardiovasc Surg Pediatr Card Surg Annu. 2004;7:180-4.

16. Jacobs JP, Jacobs ML, Maruszewski B, Lacour-Gayet FG, Tchervenkov CI, Tobota Z, et al. Initial application in the EACTS and STS Congenital Heart Surgery Databases of an empirically derived methodology of complexity adjustment to evaluate surgical case mix and results. Eur J Cardiothorac Surg. 2012;42: $775-9$.
17. O'Brien SM, Clarke DR, Jacobs JP, Jacobs ML, Lacour-Gayet FG, Pizarro C, et al. An empirically based tool for analyzing mortality associated with congenital heart surgery. J Thorac Cardiovasc Surg. 2009;138:1139-53.

18. Jacobs JP, Jacobs ML, Mavroudis C, Maruszewski B, Tchervenkov CI, LacourGayet FG, et al. What is operative morbidity? Defining complications in a surgical registry database: a report from the STS Congenital Database Taskforce and the Joint EACTS-STS Congenital Database Committee. Ann Thorac Surg. 2007;84:1416-21.

19. Jacobs JP, Benavidez OJ, Bacha EA, Walters HL III, Jacob ML. The nomenclature of safety and quality of care for patients with congenital cardiac disease: a report of the Society of Thoracic Surgeons Congenital Database Task Force Subcommittee on Patient Safety. Cardiol Young. 2008;18(Suppl 2):81-91.

20. Ungerleider RM, Greeley WJ, Sheikh KH, Philips J, Pearce FB, Kern FH, et al. Routine use of intraoperative epicardial echocardiography and Doppler color flow imaging to guide and evaluate repair of congenital heart lesions. A prospective study. J Thorac Cardiovasc Surg. 1990;100:297-309.

21. Dragulescu A, Golding F, Van Arsdell G, Caldarone C, Mertens L, Al-Radi O, et al. The impact of additional epicardial imaging to transesophageal echocardiography on intraoperative detection of residual lesions in congenital heart surgery. J Thorac Cardiovasc Surg. 2012;143:361-7.

22. Rosenfeld HM, Gentle TL, Wernovsky G, Laussen PC, Jonas RA, Mayer JE, et al. Utility of intraoperative transesophageal echocardiography in the assessment of residual cardiac defects. Pediatr Cardiol. 1998;19:346-51.

23. Bacha EA, Marshall AC, McElhinney DB, del Nido PJ. Expanding the hybrid concept in congenital heart surgery. Semin Thorac Cardiovasc Surg Pediatr Card Surg Annu. 2007;10:146-50.

24. Holzer RJ, Sisk M, Chisolm J, Hill SL, Olshove V, Phillips A, et al. Completion angiography after cardiac surgery for congenital heart disease: complementing the intraoperative imaging modalities. Pediatr Cardiol. 2009;30:1075-82.

25. Lang P, Chipman CW, Siden H, Williams RG, Norwood WI, Castaneda AR. Early assessment of hemodynamic status after repair of tetralogy of Fallot: a comparison of 24 hour (intensive care unit) and 1 year postoperative data in 98 patients. Am J Cardiol. 1982;50:795-9.

26. Nathan M, Sadhwani A, Gauvreau K, Ware J, Agus M, Newburger J, et al. Association between Technical Performance Scores and neurodevelopmental outcomes after congenital cardiac surgery. J Thorac Cardiovasc Surg. 2014;148: 232-7.

27. Connor JA, Jenkins KJ. Factors associated with increased resource utilization for congenital heart disease. In: Wyszynski D, Correa A, eds. Congenital heart defects: From origin to treatment. New York: Oxford University Press; 2010:481-92.

28. Williams DL, Gelijns AC, Moskowitz AJ, Weinberg AD, Ng JH, Crawford E, et al. Hypoplastic left heart syndrome: valuing the survival. J Thorac Cardiovasc Surg. 2000;119:720-31.

29. Kanter RK. Post-intensive care unit pediatric hospital stay and estimated costs. Crit Care Med. 2000;28:220-3.

30. Chalom R, Raphaely RC, Costarino AT Jr. Hospital costs of pediatric intensive care. Crit Care Med. 1999;27:2079-85.

31. Ungerleider RM, Bengur AR, Kessenich AL, Liekweg RJ, Hart EM, Rice BA, et al. Risk factors for higher cost in congenital heart operations. Ann Thorac Surg. 1997;64:44-8; discussion 49.

\section{Discussion}

Dr Emile Bacha (New York, NY). Meena, a very nice presentation. It is very rare in heart surgery that one can confirm a so-called dogma, so it is nice when you see that happening. Here you are confirming, in a prospective manner no less, that a good or optimal procedure achieved during the first bypass run achieves the best possible results. You also showed that intraoperative recognition and repair of residual defects is superior in terms of outcomes to postoperative recognition and repair. I do not think anybody will argue with your findings, but it is still nice to see them proven scientifically. Your findings were particularly true for premature neonates and young infants and for higher risk categories.

Although your study was focused more on the intraoperative versus postoperative group, that is, the patients who underwent re-repair during the first operation compared with the second operation, I was really interested in the comparison you had between the NO group, no re-repair, versus the intraoperative group, 
because you could look at the data differently. You had a higher mortality in the intraoperative re-repair group versus the NO group even though you had the same length of hospital stay, but that may be determined by the patients who died and therefore you had a lower length of hospital stay. I always tended to think about these patients, those who undergo an immediate re-repair, as being equal in terms of prognosis to those who had a first excellent repair.

Could you comment on that, please?

Dr Nathan. I need to mention that the NO group included patients who underwent repair on cardiopulmonary bypass and those who had non-cardiopulmonary bypass procedures such as shunts and unifocalization, and the NO group had a much lower rate of adverse events and mortality because they represented the larger group of patients among the entire cohort. If we compared just the patients who had undergone operations on cardiopulmonary bypass, the difference would probably be much lower, and we are in the process of analyzing that data.

Dr Bacha. So you are saying the groups are not well matched?

Dr Nathan. Not adequately matched, yes.

Dr Bacha. Another surgical dogma is that the enemy of good is better, and that is one of the most difficult things a surgeon has to decide in the operating room. If you have, let's say, a mild or moderate defect but your patient is doing okay, do you go back on bypass and fix it versus do you accept it? That is a very difficult decision to make. Can your data help us decide, maybe from what you know on the technical performance score database, on that particular question?

Dr Nathan. I totally agree with you that the enemy of good is better, and we are actually in the process of developing a score that will help us determine which residual lesions need revision in the operating room versus those that can be followed. Most postoperative revisions were related to valves, and I think this is a group that needs to be studied individually rather than as part of a large cohort. We are in the process of collecting and analyzing data from this group of patients.

Dr Bacha. The third question is regarding the issue of timing of the diagnosis of the residual defect, because I think it makes a difference whether you are reoperating the next day for a major residual defect versus 2 weeks or before discharge, let's say. Do you have any comments on the timing? Was that a factor?

Dr Nathan. The numbers are fairly small, so we could not look at each individual time point of reintervention, but most of the postoperative revisions were more than 48 hours after surgery.

Dr Bacha. Did that make a difference?

Dr Nathan. We have not looked at that specifically because the numbers were too small to do a meaningful analysis.

Dr Bacha. And the last question. The most common type of rerepair was a left AV valve repair. You would expect that, especially if you have a large valve practice. Now, you could argue that if you are doing complex left AV valve repairs, sometimes you simply have to come off bypass, look at your TEE, and then go back on bypass almost in a planned manner. Those were counted as re-repairs.

Do you think you should differentiate between valve re-repairs versus nonvalve re-repairs such as residual aortic arch obstructions, or residual VSDs that may potentially carry a worse prognosis?

Dr Nathan. Thank you very much. I think that is really worth exploring and we will proceed to do so.
Dr Christian Pizarro (Wilmington, Del). Meena, a great presentation and very interesting study. I wonder if you had the opportunity to look at the use of extracorporeal membrane oxygenation (ECMO) in those patients who had residual lesions who were intervened on postoperatively? Not infrequently sometimes there are some of those lesions, the circulation is precarious, and patients are not in good condition. Did you explore about how that use of ECMO early with a plan to go to the operating room, let's say, the next day or so could have affected the outcome?

Dr Nathan. We did look at ECMO, but it was included as a composite in the adverse events, because, again, the numbers in each of the groups were small so that comparison using an individual adverse event was difficult.

Dr Pizarro. And then just briefly, among those patients who had a postoperative intervention, how many of those had a residual lesion that was identified in the operating room but deemed probably not to be important enough? That goes to the judgment at the time, should I leave this, should I act on it?

Dr Nathan. Among the valve repairs, at least on intraoperative assessment, the regurgitation was usually at least a grade or two lower than in later postoperative echocardiograms, so those could not be picked up intraoperatively. Thus several valve repairs that occurred postoperatively had an increase in grade of regurgitation that necessitated their repair

Dr Mark Danton (Glasgow, Scotland, UK). From your data, obviously it is best to repair any residual lesion at the time of the first operation. So with respect to the residual lesions that required repair at a second or subsequent operation, were those new lesions, first identified in the postoperative phase, or were they lesions recognized at initial surgery but progressed over time, or finally was the gravity of lesion underappreciated at the time of intraoperative assessment. If it were the case that the significance of the residual lesion was underestimated at surgery, is there a better way of identifying them and their significance at the first operation so that you do not have to deal with them at a subsequent operation?

Dr Nathan. A small percentage of the valve re-repairs postoperatively were related to an increase in regurgitation grade related to either a torn stitch or new additional regurgitation that was not identified in the operating room. So I think intraoperative assessment should not only include a good echo, it should also include clinical assessment, which is what all of us do in the operating room. And we are in the process of trying to define the intraoperative echo findings that match the postoperative echo findings that will identify which intraoperative echo findings require a revision. We are currently in the process of comparing intraoperative echos to postoperative echos to arrive at cut points that will define better when we should intervene in the operating room compared with postoperatively.

Dr Matthias Siepe (Freiburg, Germany). Excellent study. Thank you. I am a little bit confused about those patients who required a catheter-based intervention. In which group did you put those patients? Or should there be a fifth group with catheter-based reinterventions?

Dr Nathan. Currently these patients are included in the postoperative revisions, because some of the patients did require postoperative pulmonary artery stenting or dilation. The numbers are fairly small, but we will try and analyze that group as a separate group and see if there is a difference. 

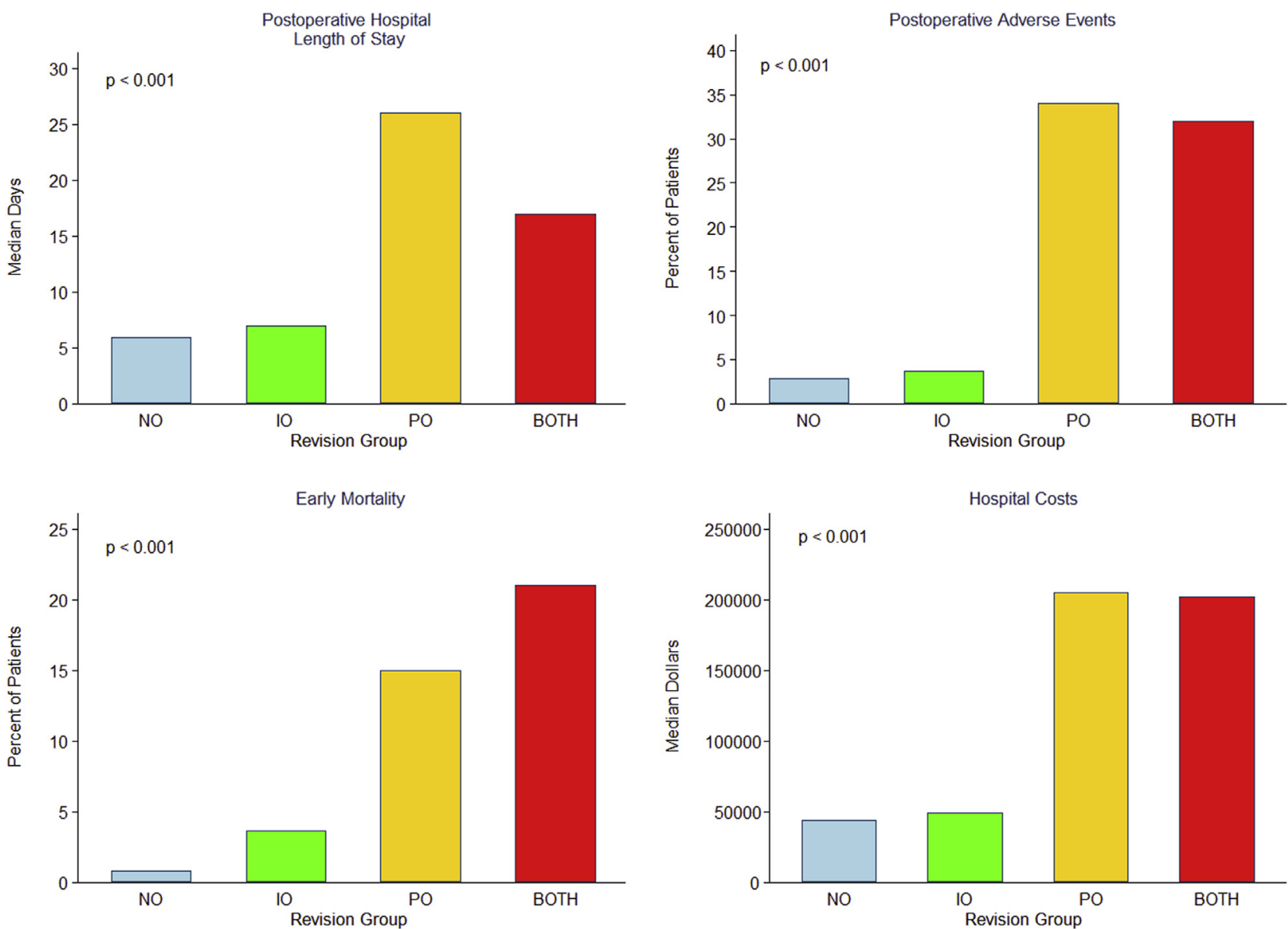

FIGURE E1. Association between revision groups and outcomes. $N O$, No revisions; $I O$, intraoperative revisions; $P O$, postoperative revisions; $B O T H$, both intraoperative and postoperative revisions. 
TABLE E1. Intraoperative revisions for residual lesions $(\mathbf{n}=\mathbf{8 1})$

\begin{tabular}{|c|c|c|c|}
\hline Type of repair & n & Type of repair & $\mathbf{n}$ \\
\hline Aortic root repair & 1 & $\begin{array}{l}\text { Partial anomalous pulmonary } \\
\text { venous return patch } \\
\text { revision }\end{array}$ & 3 \\
\hline Aortic valve repair & 9 & $\begin{array}{l}\text { Pulmonary valve } \\
\text { repositioning }\end{array}$ & 1 \\
\hline Ascending aortic patch & 1 & $\begin{array}{l}\text { Pulmonary vein baffle in } \\
\text { Senning }\end{array}$ & 1 \\
\hline $\begin{array}{l}\text { Bidirectional Glenn } \\
\text { (after Cone) }\end{array}$ & 1 & $\begin{array}{l}\text { Pulmonary vein vent site } \\
\text { repair }\end{array}$ & 1 \\
\hline $\begin{array}{l}\text { Branch pulmonary artery } \\
\text { augment }\end{array}$ & 2 & $\begin{array}{l}\text { Right atrioventricular valve } \\
\text { repair }\end{array}$ & 14 \\
\hline $\begin{array}{l}\text { Blalock-Taussig shunt } \\
\text { revision }\end{array}$ & 1 & $\begin{array}{l}\text { Residual left ventricular } \\
\text { outflow tract obstruction }\end{array}$ & 5 \\
\hline $\begin{array}{l}\text { Conversion to transannular } \\
\text { patch }\end{array}$ & 3 & $\begin{array}{l}\text { Residual ventricular septal } \\
\text { defect }\end{array}$ & 14 \\
\hline Coronary button revision & 3 & $\begin{array}{l}\text { Right ventricular outflow } \\
\text { tract revision }\end{array}$ & 3 \\
\hline $\begin{array}{l}\text { Left atrioventricular valve } \\
\text { repair }\end{array}$ & 23 & $\begin{array}{l}\text { Right ventricle-pulmonary } \\
\text { artery conduit }\end{array}$ & 1 \\
\hline $\begin{array}{l}\text { Left atrioventricular valve } \\
\text { replacement }\end{array}$ & 1 & $\begin{array}{l}\text { Superior vena cava stenosis } \\
\text { repair }\end{array}$ & 1 \\
\hline $\begin{array}{l}\text { Left ventricle-aorta baffle } \\
\text { enlargement }\end{array}$ & 3 & $\begin{array}{l}\text { Ventricular septal defect } \\
\text { patch fenestration }\end{array}$ & 1 \\
\hline Main pulmonary artery patch & 1 & & \\
\hline
\end{tabular}

Some patients had more than 1 reintervention.
TABLE E2. Postoperative operative revisions for residual lesions $(\mathbf{n}=\mathbf{1 2 8})$

\begin{tabular}{lrlr}
\hline \multicolumn{1}{c}{ Type of repair } & n & \multicolumn{1}{c}{ Type of repair } & n \\
\hline Aortic valve repair & 5 & Main pulmonary artery & 2 \\
& & ligation for dual PBF & \\
Aortic valve balloon dilation & 1 & Mustard baffle revision & 1 \\
Aortic valve replacement & 2 & Orthotopic heart transplant & 1 \\
Atrial septal defect balloon & 4 & Pulmonary artery band & 1
\end{tabular}

Atrial septal defect balloon

Pulmonary artery band dilation/stent

Azygos stent

Bidirectional Glenn

Bidirectional Glenn balloon dilation

Bidirectional Glenn take-down

Branch pulmonary artery balloon dilation/stent

Bronchus dilation/stenting

Blalock-Taussig shunt balloon dilation/stent

Blalock-Taussig revision/ conversion/insertion

Coil APC/VVC (for failed ligation in to operating room)

Fenestrated atrial septal defect closure

1 Pulmonary artery band $\quad 1$ revision

2 partial anomalous pulmonary 1 venous return revision

1 PDA ligation

1 Permanent pacemaker

24 Pulmonary vein balloon 12 dilation

1 Right atrioventricular valve 9 repair

2 Right atrioventricular valve 3 replacement

5 Residual atrial septal defect 3 repair

2 Residual ventricular septal 5 defect repair

1 Right ventricular outflow 8 tract revision

Fontan fenestration closure

Fontan Fenestration stent

Fontan stent

Fontan take-down

Left atrioventricular valve balloon dilation

Left atrioventricular valve repair

Left atrioventricular valve replacement

Left circumflex balloon dilation

Left ventricular outflow tract myectomy

Some patients had more than 1 reintervention. $A P C$, Aortopulmonary collaterals; $V V C$, veno-venous collaterals; $P B F$, pulmonary blood flow; $P D A$, patent ductus arteriosus. 
TABLE E3. Both intraoperative and postoperative revisions for residual lesions $(n=19)$

\begin{tabular}{|c|c|c|c|}
\hline \multicolumn{2}{|l|}{ Intraoperative reintervention ( $\mathrm{n}=19$; same patients) } & \multicolumn{2}{|c|}{ Postoperative reintervention $(n=19 ;$ same patients $)$} \\
\hline Type of repair & $\mathbf{n}$ & Type of repair & $\mathbf{n}$ \\
\hline Atrial septal defect closure & 1 & Atrioventricular valve repair/replacement & 7 \\
\hline Atrioventricular valve re-repair & 14 & Damus-Kaye-Stansel revision & 1 \\
\hline Coronary button revision & 1 & Pulmonary artery band take-down & 1 \\
\hline Damus-Kaye-Stansel revision for coronary malperfusion & 1 & Pulmonary artery dilation & 3 \\
\hline Residual ventricular septal defect closure or enlargement of patch & 2 & Permanent pacemaker & 10 \\
\hline Systemic vein re-repair & 1 & Residual ventricular septal defect/atrial septal defect & 2 \\
\hline Ventricular septal defect fenestration & 1 & Ross & 1 \\
\hline
\end{tabular}

Some patients had more than 1 reintervention.

TABLE E4. Unadjusted associations between outcomes: postoperative hospital length of stay, postoperative adverse events, early mortality, total hospital costs, and patient risk factors

\begin{tabular}{|c|c|c|c|c|}
\hline & $\begin{array}{c}\text { Postoperative hospital } \\
\text { length of stay, } \\
\text { median (IQR) days } \\
\end{array}$ & $\begin{array}{c}\text { Postoperative } \\
\text { adverse events, } \mathbf{n}(\%)\end{array}$ & $\begin{array}{c}\text { Early mortality, } \\
\text { n (\%) } \\
\end{array}$ & $\begin{array}{l}\text { Total hospital costs, } \\
\text { median (IQR) US\$ }\end{array}$ \\
\hline \multicolumn{5}{|c|}{ Extracardiac/genetic anomalies/syndromes } \\
\hline Yes $(n=390)$ & $8(5,17)$ & $26(7)$ & $17(4)$ & $50,979(36,898,117,471)$ \\
\hline No $(n=1496)$ & $7(4,12)$ & $74(5)$ & $22(1)$ & $46,608(32,795,85,687)$ \\
\hline \multicolumn{5}{|l|}{ Prematurity } \\
\hline Yes $(\mathrm{n}=145)$ & $13(7,29)$ & $29(20)$ & $15(10)$ & $88,809(46,495,200,018)$ \\
\hline No $(n=1741)$ & $7(4,12)$ & $71(4)$ & $24(1)$ & $46,048(32,924,85,369)$ \\
\hline \multicolumn{5}{|l|}{ Age } \\
\hline Neonates $(\mathrm{n}=315)$ & $16(10,27)$ & $47(15)$ & $21(7)$ & $111,546(79,540,176,315)$ \\
\hline Infants $(\mathrm{n}=582)$ & $7(5,14)$ & $33(6)$ & $14(2)$ & $48,486(35,922,92,088)$ \\
\hline Children $(\mathrm{n}=989)$ & $5(4,8)$ & $20(2)$ & $4(<1)$ & $39,373(29,060,57,610)$ \\
\hline \multicolumn{5}{|l|}{ RACHS-1 risk categories } \\
\hline $1(\mathrm{n}=164)$ & $3(3,4)$ & $0(0)$ & $0(0)$ & $23,759(22,235,26,383)$ \\
\hline $2(\mathrm{n}=586)$ & $5(4,7)$ & $11(2)$ & $4(1)$ & $38,057(30,822,50,245)$ \\
\hline $3(\mathrm{n}=676)$ & $8(5,13)$ & $24(4)$ & $6(1)$ & $52,701(38,366,87,610)$ \\
\hline $4(n=208)$ & $12(8,21)$ & $27(13)$ & $13(6)$ & $90,416(60,666,146,345)$ \\
\hline $6(\mathrm{n}=71)$ & $26(18,41)$ & $18(25)$ & $7(10)$ & $154,915(122,687,250,282)$ \\
\hline $7(\mathrm{n}=181)($ not categorized $)$ & $11(7,25)$ & $20(11)$ & $9(5)$ & $86,190(49,902,170,395)$ \\
\hline \multicolumn{5}{|l|}{ STAT mortality categories } \\
\hline $1(\mathrm{n}=650)$ & $5(4,6)$ & $6(1)$ & $1(<1)$ & $33,389(26,327,43,800)$ \\
\hline $2(\mathrm{n}=525)$ & $6(5,10)$ & $14(3)$ & $2(<1)$ & $44,104(34,526,70,601)$ \\
\hline $3(\mathrm{n}=183)$ & $9(7,16)$ & $9(5)$ & $3(2)$ & $66,888(44,487,102,814)$ \\
\hline $4(n=376)$ & $12(7,21)$ & $44(12)$ & $20(5)$ & $90,552(60,390,148,551)$ \\
\hline $5(\mathrm{n}=105)$ & $20(14,33)$ & $23(22)$ & $10(10)$ & $136,715(96,206,215,038)$ \\
\hline $6(\mathrm{n}=47)($ not categorized $)$ & $10(7,18)$ & $4(9)$ & $3(6)$ & $85,554(47,365,136,999)$ \\
\hline
\end{tabular}


TABLE E5. Subgroup analysis of outcomes: postoperative hospital length of stay, postoperative adverse events, early mortality, and total hospital costs based on patient age and valve intervention at index surgery

\begin{tabular}{|c|c|c|c|c|c|c|c|c|}
\hline & $\begin{array}{c}\text { Postoperative hospital } \\
\text { length of stay, } \\
\text { median (IQR) days } \\
\end{array}$ & $P$ value & $\begin{array}{c}\text { Postoperative } \\
\text { adverse } \\
\text { events, } \% \\
\end{array}$ & $P$ value & $\begin{array}{c}\text { Early } \\
\text { mortality, \% } \\
\end{array}$ & $P$ value & $\begin{array}{l}\text { Total hospital costs, } \\
\text { median (IQR) US\$ }\end{array}$ & $P$ value \\
\hline \multicolumn{9}{|l|}{ Revision group } \\
\hline None (1658) & $6(4,11)$ & \multirow[t]{3}{*}{$<.001$} & 2.9 & \multirow[t]{3}{*}{$<.001$} & 0.8 & \multirow[t]{3}{*}{$<.001$} & $44,504(32,134,78,342)$ & \multirow[t]{3}{*}{$<.001$} \\
\hline Intraoperative (81) & $7(5,11)$ & & 3.7 & & 3.7 & & $49,427(37,552,81,592)$ & \\
\hline Postoperative (128) & $26(14,63)$ & & 33.6 & & 14.8 & & $204,750(99,061,427,594)$ & \\
\hline \multicolumn{9}{|l|}{ Valve interventions } \\
\hline None (842) & $6(5,10)$ & \multirow[t]{3}{*}{$<.001$} & 1.9 & \multirow[t]{3}{*}{$<.001$} & 0.4 & \multirow[t]{3}{*}{$<.001$} & $44,073(34,173,72,493)$ & \multirow[t]{3}{*}{$<.001$} \\
\hline Intraoperative (61) & $6(5,10)$ & & 3.3 & & 3.3 & & $44,919(37,552,65,311)$ & \\
\hline Postoperative (65) & $21(12,56)$ & & 23.1 & & 7.7 & & $169,384(86,990,448,581)$ & \\
\hline \multicolumn{9}{|l|}{ No valve interventions } \\
\hline None (816) & $7(4,12)$ & \multirow[t]{3}{*}{$<.001$} & 3.9 & \multirow[t]{3}{*}{$<.001$} & 1.2 & \multirow[t]{3}{*}{$<.001$} & $46,092(29,237,83,393)$ & \multirow[t]{3}{*}{$<.001$} \\
\hline Intraoperative (20) & $12(7,19)$ & & 5.0 & & 5.0 & & $94,171(43,226,131,541)$ & \\
\hline Postoperative (63) & $33(15,63)$ & & 44.4 & & 22.2 & & $211,033(134,530,418,492)$ & \\
\hline \multicolumn{9}{|l|}{ Age $<1$ y } \\
\hline None (263) & $15(10,24)$ & \multirow[t]{3}{*}{$<.001$} & 8.8 & \multirow[t]{3}{*}{$<.001$} & 2.3 & \multirow[t]{3}{*}{$<.001$} & $100,835(76,204,141,127)$ & \multirow[t]{3}{*}{$<.001$} \\
\hline Intraoperative (9) & $13(11,19)$ & & 22.2 & & 22.2 & & $104,879(92,281,254,696)$ & \\
\hline Postoperative (39) & $35(21,57)$ & & 46.2 & & 25.6 & & $244,920(172,280,396,683)$ & \\
\hline \multicolumn{9}{|l|}{ Age $1-17$ y } \\
\hline None (1395) & $6(4,9)$ & \multirow[t]{3}{*}{$<.001$} & 1.8 & \multirow[t]{3}{*}{$<.001$} & 0.5 & \multirow[t]{3}{*}{$<.001$} & $40,034(30,465,59,459)$ & \multirow[t]{3}{*}{$<.001$} \\
\hline Intraoperative (72) & $7(5,10)$ & & 1.4 & & 1.4 & & $45,994(37,101,68,260)$ & \\
\hline Postoperative (89) & $19(12,68)$ & & 28.7 & & 10.1 & & $146,682(87,297,452,752)$ & \\
\hline
\end{tabular}

$I Q R$, Interquartile range. 
TABLE E6. Characteristics and outcomes of patients with major residual lesions who required postoperative interventions, those who did not require intervention, and others

\begin{tabular}{|c|c|c|c|c|}
\hline & $\begin{array}{c}\text { Major residual lesions } \\
\text { with intervention } \\
\text { before discharge }\end{array}$ & $\begin{array}{c}\text { Major residual lesions } \\
\text { with no intervention } \\
\text { before discharge }\end{array}$ & All others & $P$ value \\
\hline Number in group & 145 & 98 & 1643 & \\
\hline Median age, y (range) & $0.5(1 \mathrm{~d}-15.5)$ & $0.9(1 \mathrm{~d}-17.6)$ & $1.4(1 \mathrm{~d}-17.9)$ & $<.001$ \\
\hline Prematurity, n (\%) & $20(14)$ & $12(12)$ & $113(7)$ & .004 \\
\hline Extracardiac/genetic anomalies/syndromes & $36(25)$ & $26(27)$ & $328(20)$ & .12 \\
\hline \multicolumn{5}{|l|}{ RACHS-1 risk category, $\mathrm{n}(\%)$} \\
\hline $1(164)$ & $1(1)$ & $0(0)$ & $163(10)$ & $<.001$ \\
\hline $2(586)$ & $17(12)$ & $19(19)$ & $550(33)$ & \\
\hline $3(676)$ & $55(38)$ & $57(58)$ & $564(34)$ & \\
\hline $4(208)$ & $27(19)$ & $13(13)$ & $168(10)$ & \\
\hline $6(71)$ & $13(9)$ & $3(3)$ & $55(3)$ & \\
\hline 7 (181) (not categorized) & $32(22)$ & $6(6)$ & $143(9)$ & \\
\hline \multicolumn{5}{|l|}{ STAT mortality category, $\mathrm{n}(\%)$} \\
\hline $1(650)$ & $9(6)$ & $18(18)$ & $623(38)$ & $<.001$ \\
\hline $2(525)$ & $33(23)$ & $40(41)$ & $452(28)$ & \\
\hline $3(183)$ & $14(10)$ & $15(15)$ & $154(9)$ & \\
\hline $4(376)$ & $66(46)$ & $19(19)$ & $291(18)$ & \\
\hline $5(105)$ & $17(12)$ & $5(5)$ & $83(5)$ & \\
\hline $6(47)($ not categorized $)$ & $6(4)$ & $1(1)$ & $40(2)$ & \\
\hline $\begin{array}{l}\text { Median postoperative hospital length of stay, } \\
\text { d (25th, } 75 \text { th percentiles) }\end{array}$ & $23(13,56)$ & $9(5,17)$ & $6(4,10)$ & $<.001$ \\
\hline Postoperative adverse events, n (\%) & $47(32.4)$ & $9(9.2)$ & $44(2.7)$ & $<.001$ \\
\hline Early mortality, n (\%) & $23(15.9)$ & $5(5.1)$ & $11(0.7)$ & $<.001$ \\
\hline $\begin{array}{l}\text { Median total hospital costs, } \\
\text { US\$ (25th, } 75 \text { th percentiles) }\end{array}$ & $203,572(99,255,402,592)$ & $61,141(42,758,115,123)$ & $44,104(31,985,76,899)$ & $<.001$ \\
\hline
\end{tabular}

TABLE E7. Patient characteristics and outcomes by 3 revision groups (BOTH group excluded)

\begin{tabular}{|c|c|c|c|c|}
\hline & No revisions & $\begin{array}{l}\text { Intraoperative revision } \\
\text { of residual lesion }\end{array}$ & $\begin{array}{l}\text { Postoperative revision } \\
\text { of residual lesion }\end{array}$ & $P$ value \\
\hline Number in group & 81 & 81 & 81 & \\
\hline Median age, y (range) & $2.2(1 \mathrm{~d}-16.6)$ & $1.9(1 \mathrm{~d}-16.5)$ & $1.3(1 \mathrm{~d}-15.5)$ & .43 \\
\hline Prematurity, n (\%) & $5(6)$ & $5(6)$ & $7(9)$ & .86 \\
\hline Extracardiac/genetic anomalies/syndromes & $21(26)$ & $21(26)$ & $21(26)$ & 1.0 \\
\hline \multicolumn{5}{|l|}{ RACHS-1 risk category, $\mathrm{n}(\%)$} \\
\hline $1(7)$ & $3(4)$ & $3(4)$ & $1(1)$ & .69 \\
\hline $2(68)$ & $25(31)$ & $25(31)$ & $18(22)$ & \\
\hline $3(125)$ & $41(51)$ & $41(51)$ & $43(53)$ & \\
\hline $4(26)$ & $8(10)$ & $8(10)$ & $10(12)$ & \\
\hline $6(0)$ & $0(0)$ & $0(0)$ & $0(0)$ & \\
\hline 7 (17) (not categorized) & $4(5)$ & $4(5)$ & $9(11)$ & \\
\hline $\begin{array}{l}\text { Median postoperative hospital length of stay, } \\
\text { d (25th, 75th percentiles) }\end{array}$ & $6(4,9)$ & $7(5,11)$ & $18(12,44)$ & $<.001$ \\
\hline Postoperative adverse events, $\mathrm{n}(\%)$ & $36(3.7)$ & $3(3.7)$ & $21(26)$ & $<.001$ \\
\hline Early mortality, n (\%) & $2(2.5)$ & $3(3.7)$ & $6(7.4)$ & .40 \\
\hline $\begin{array}{l}\text { Median total hospital costs, } \\
\text { US\$ (25th, 75th percentiles) }\end{array}$ & $44,118(31,062,66,765)$ & $49,427(37,552,81,592)$ & $140,430(86,990,341,506)$ & $<.001$ \\
\hline
\end{tabular}

